\title{
Modelling annual mass balances of eight Scandinavian glaciers using statistical models
}

\author{
M. Trachsel ${ }^{1}$ and A. Nesje ${ }^{2}$ \\ ${ }^{1}$ Department of Biology, Bergen, Norway \\ ${ }^{2}$ Department of Earth Science and Uni Climate, Bergen, Norway \\ Correspondence to: M. Trachsel (mathias.trachsel@uib.no) and A. Nesje (atle.nesje@uib.no) \\ Received: 15 December 2014 - Published in The Cryosphere Discuss.: 15 January 2015 \\ Revised: 25 June 2015 - Accepted: 4 July 2015 - Published: 31 July 2015
}

\begin{abstract}
Mass balances of Scandinavian glaciers are mainly influenced by winter precipitation and summer temperature. We used simple statistical models to assess the relative importance of summer temperature and winter precipitation for annual balances of eight glaciers in Scandinavia. Winter precipitation was more important for maritime glaciers, whereas summer temperature was more important for annual balances of continental glaciers. Most importantly relative importances of summer temperature and winter precipitation were not stable in time. For instance, winter precipitation was more important than summer temperature for all glaciers in the 25-year period 1972-1996, whereas the relative importance of summer temperature was increasing towards the present. Between 1963 and 1996 the Atlantic Multidecadal Oscillation (AMO) index was consistently negative and the North Atlantic Oscillation (NAO) Index was consistently positive between 1987 and 1995, both being favourable for glacier growth. Winter precipitation was more important than summer temperature for annual balances when only considering subsets of years with high NAO-index and negative AMO-index, respectively, whereas the importance of summer temperature was increased analysing subsets of years with low NAO-index and positive AMO-index, respectively. Hence, the relative importance of precipitation and temperature for mass balances was probably influenced by the state of the AMO and the NAO, as these two indexes are associated with changes in summer temperature (AMO) and winter precipitation (NAO).
\end{abstract}

\section{Introduction}

Glaciers respond to climate change because their mass balance and extent are mainly a result of variations in winter accumulation and summer ablation. Over time, glacier changes exhibit some of the clearest evidence of variations in the earth's climate system. As a result, glaciers are key indicators of global, regional and local climate change (IPCC, 2007, 2013). Past (e.g. Nesje, 2009), present (e.g. Andreassen and Oerlemans, 2009) and future (e.g. Giesen and Oerlemans, 2010) of Scandinavian glaciers has been studied extensively. The accumulation on Scandinavian glaciers is mainly a result of winter precipitation (as snow) and wind redistribution of snow, whereas glacier ablation is more complex and depends on the total energy available for melt. Accumulation and ablation processes of Scandinavian glaciers have been extensively studied by means of mass balance models of varying complexity (e.g. Andreassen et al., 2006; Andreassen and Oerlemans, 2009; Engelhardt et al., 2013; Giesen and Oerlemans, 2010; Hock et al., 2007; Laumann and Nesje, 2009a, b, 2014; Oerlemans, 1992, 1997; Rasmussen and Conway, 2005; Rasmussen et al., 2007; Schuler et al., 2005). Most of these studies have focused on estimating sensitivities of winter balances, summer balances and annual balances to changes in temperature and precipitation. Many studies provided projections of future mass balances based on climate projections (e.g. Giesen and Oerlemans, 2010). Climate sensitivities are absolute influences of temperature and precipitation changes on mass balances. They are, however, measured in different units and are therefore difficult to compare directly $(\Delta \mathrm{m}$ w.e. for changes in $\mathrm{K}$ and in $\%$ of precipitation). It is possible to directly deduce from climate sensitivi- 
ties that changes in temperature are more important for continental glaciers than for maritime glaciers in southern Norway, as a larger change in precipitation is needed to counterbalance a temperature change of $1 \mathrm{~K}$. But it is not possible to directly assess if changes in temperature or precipitation are more important for the annual balances of one glacier. Relative and thereby directly comparable sensitivities of annual balances to changes in temperature and precipitation are therefore not obtained from climate sensitivities.

Further studies have explicitly assessed the relative importance of winter balance and summer balance for annual balance by correlating the summer and winter balances with annual balance (Nesje et al., 2000). Nesje et al. (2000) showed that the correlation between winter balance and annual balance is higher than the correlation between summer balance and annual balance for maritime glaciers and vice versa for continental glaciers. Mernild et al. (2014) replicated this analysis using data from 1970 to 2009. Andreassen et al. (2005) used ratios of standard deviations of winter balances (sBw) to standard deviations of annual balances $(\mathrm{sBa}, \mathrm{sBw} / \mathrm{sBa})$ and standard deviations of summer balances (sBs) to standard deviations of annual balances (sBs / sBa) to assess the relative importance of summer and winter balance for the annual balance. These ratios are direct measures of the relative importance of summer balance and winter balance for annual balances. Hence absolute influences of temperature and precipitation on annual balances as well as relative influences of winter and summer balance on annual balances have been assessed. In this study, we combine these two approaches and focus on determining relative and thereby directly comparable importances of winter precipitation and summer temperature for annual balances of glaciers in Scandinavia.

Assessing the relative importance of seasonally averaged summer temperature and winter precipitation for annual balances and possible changes in time is especially interesting in light of palaeoclimatological interpretation of glacier records. In palaeoclimatology, at best summer temperature, winter precipitation and annual balance reconstructions are available and attempts have been made to reconstruct winter precipitation based on glacier reconstructions and independent summer temperature reconstructions (e.g. Bakke et al., 2005).

There are well-known transient phases of positive annual balances (e.g. 1987-1995, e.g. Nesje et al., 2000). It is therefore interesting to assess if the relative importance of summer temperature and winter precipitation for annual balance changes through time. Until now, attempts of quantifying temporal changes of summer balance and winter balance on annual balance have been constrained to estimating running means of summer and winter balances and comparing the absolute values of these running means (e.g. Engelhardt et al., 2013). However, a direct assessment of temporal changes of the relative importance of summer temperature and winter precipitation for annual balances is still missing. Cumula- tive annual balances show clear patterns of consistently positive mass balances and thereafter consistently negative mass balances (e.g. Nesje et al., 2000, Fig. 3). We therefore hypothesise that the relative importance of summer temperature and winter precipitation for annual balances is not stable in time and that there is a large-scale forcing mechanism causing these changes. These forcings could either be of atmospheric or oceanic origin. It is, for instance, well known that increased amounts of winter precipitation in Scandinavia are associated with stronger zonal moisture advection that is due to pressure differences between Iceland and the Azores (e.g. Wanner et al., 2001). These pressure differences are summarized by the North Atlantic Oscillation (NAO) Index. In addition to the atmosphere, systematic changes in ocean temperatures may also influence the relative importance of summer temperature and winter precipitation for annual balances of glaciers in Scandinavia. The Atlantic Multidecadal Oscillation (AMO) is a pattern of changing sea-surface temperatures in the North Atlantic (e.g. Schlesinger and Ramankutty, 1994). Changing sea surface temperatures might result in changing temperatures over land and thereby also alter the relative importance of summer temperature and winter precipitation for annual balances.

In this study, we focus on assessing the relative importance of winter precipitation and summer temperature for annual mass balances, temporal changes of these influences and on possible influences of large-scale atmospheric and oceanic patterns on these temporal changes. The aims of this study are therefore threefold: (i) model the annual mass balances of eight Scandinavian glaciers with long annual mass balance series using a suite of statistical models using seasonally averaged climate data as input variables. These models enable us to compare the relative importance of winter precipitation and summer temperature for annual mass balances of glaciers; (ii) assessing temporal changes of relative importances of winter precipitation and summer temperature. (iii) Compare these temporal changes to large-scale oceanic and atmospheric modes, such as the Atlantic Multidecadal Oscillation (AMO) and the North Atlantic Oscillation (NAO).

\section{Data and methods}

\subsection{Data}

We modelled the mass balances of eight glaciers in Scandinavia: Ålfotbreen (ALF), Rembesdalskåka (REM), Nigardsbreen (NIG), Storbreen (STO), Hellstugubreen (HEL), Gråsubreen (GR) in southern Norway and Engabreen (ENG) and Storglaciären (STORGL) in northern Norway and northern Sweden, respectively (Fig. 1). Storglaciären has the longest annual mass balance time series, beginning in 1946 and Engabreen has the shortest time series, initiated in 1970. For all glaciers, data until 2010 were considered. Glacier mass balance data are available at www.nve.no/bre 


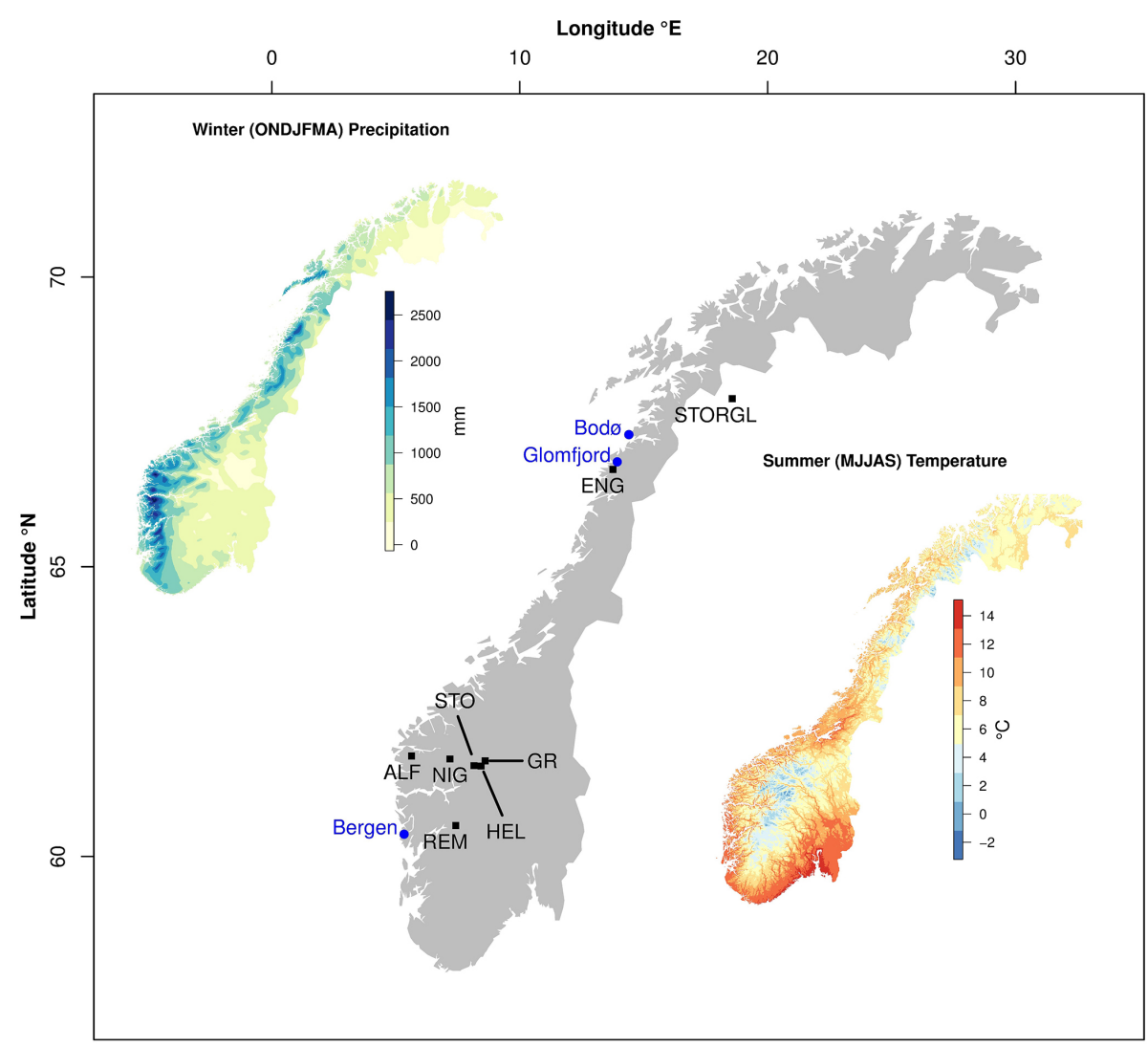

Figure 1. Map of glaciers and summer temperature and winter precipitation. Glaciers: Ålfotbreen (ALF), Rembesdalsskåka (REM), Nigardsbreen (NIG), Storbreen (STO), Hellstugubreen (HEL), Gråsubreen (GR), Engabreen (ENG) and Storglaciären (STORGL). Meteorological stations Bergen, Glomfjord and Bodø are indicated. Inset maps show 1961-1990 normal summer (MJJAS) temperature and winter (ONDJFMA) precipitation (data available at http://met.no/Klima/Klimastatistikk and processed in R).

(Kjøllmoen, 2011; Andreassen and Winsvold, 2012) and bolin.su.se/data/tarfala. For all glaciers, winter balances, summer balances and annual balances are available. Uncertainties of mass balance measurements and their possible sources are thoroughly discussed in Andreassen et al. (2005) and are estimated to between \pm 0.2 and $\pm 0.4 \mathrm{~m}$ w.e. per year.

Cumulative mass balance changes are shown in Fig. 3. The three maritime glaciers Ålfotbreen (ALF), Rembesdalsskåka (REM), and Nigardsbreen (NIG) in southern Norway and the maritime glacier Engabreen (ENG) in northern Norway show positive cumulative annual balances between the initiation of the measurements and 2010 (Fig. 3). Mass balances are especially positive during the first half of the 1990s. The continental glaciers Storbreen (STO), Hellstugubreen (HEL), and Gråsubreen (GR) in southern Norway and the continental glacier Storglaciären (STORGL) in northern Sweden experienced negative cumulative mass balances between the start of the measurements and 2010. For these glaciers the mass balance loss was reduced in the first half of the 1990s.

We used meteorological data from the meteorological station Bergen-Florida to model mass balances in southern Norway. We decided to exclusively use precipitation data from
Bergen-Florida for all glaciers in southern Norway since Bergen-Florida records the large synoptic weather systems and is not affected by local topographic effects that are affecting meteorological stations in the deep and narrow valleys closer to the glaciers studied (e.g. Nesje, 2005). For glaciers in northern Scandinavia, we used meteorological data from the coastal station Glomfjord available from the beginning of the mass balance series. The temperature measurements are continuous, but the precipitation series ends in 2003. We extended the precipitation series with data from the nearby Bodø meteorological station. The precipitation data from Bod $\varnothing$ were scaled to the data from Glomfjord in the period of overlap (1953-2003) of the two data series.

\subsection{Methods}

To directly quantify the relative importances of summer temperature and winter precipitation on annual balances, we used a suite of three statistical models with increasing complexity and number of parameters that needed to be estimated: 
(i) Linear models using a climate index as independent variable,

(ii) Linear models using summer temperature and winter precipitation as independent variables,

(iii) Additive models using summer temperature and winter precipitation as independent variables.

If the variance explained by two models was not significantly different, we favoured the simpler model, as it was more parsimonious.

As glaciers are mainly sensitive to summer temperatures and winter precipitation, models were run using one summer temperature and one winter precipitation as independent variables. We tested the influences of two summer temperatures, namely temperatures from May-September ( $T$ MJJAS) and temperatures from June-August ( $T$ JJA), and two winter precipitation variables, precipitation October to April $(P$ ONDJFMA) and precipitation from November-March $(P$ NDJFM) on annual glacier mass balances. This resulted in a total of four possible combinations of input variables. We chose the combination that resulted in the lowest Akaike information criterion (AIC).

\subsubsection{Climate indices}

The simplest way of modelling the influence of (winter) precipitation and (summer) temperature on glacier mass balances is to generate a climate index, where winter precipitation and summer temperature are equally weighted (Imhof et al., 2012; Nesje, 2005), i.e. they are assigned the same relative importance for the annual balance. This was achieved by standardising summer temperature and winter precipitation and subtracting standardised summer temperature from standardised winter precipitation, as the two variables have opposed influences.

$z=\left(\frac{\boldsymbol{P}-\bar{P}}{s_{P}}\right)-\left(\frac{\boldsymbol{T}-\bar{T}}{s_{T}}\right)$

$\boldsymbol{y}=a+b \cdot z$

where $z$ is the climate index, $P$ winter precipitation, $T$ summer temperature, $s$ are standard deviations, bars denote means, $y$ is the annual mass balance and $a$ and $b$ are regression coefficients.

\subsubsection{Linear models}

Annual mass balances were modelled using linear models with one (summer) temperature and one (winter) precipitation variable as independent variables. In a first step, we tested interactions between (summer) temperature and (winter) precipitation and quadratic terms for significance. F-tests indicated that neither interaction terms, nor quadratic terms were significant $(p<0.05)$.
The linear regression equation

$\boldsymbol{y}=a+b_{1} \cdot \boldsymbol{x}_{1}+b_{2} \cdot \boldsymbol{x}_{2}$

is interpreted as follows: if $x_{2}$ is kept constant and $x_{1}$ is changed by one unit, y changes by $b_{1}$ units (e.g. Legendre and Legendre, 2012). Hence the regression coefficients of unscaled variables are also the climate sensitivity of this variable. Usually, $x_{1}$ and $x_{2}$ are measured in different units hampering the comparison of the influence of the two variables on $y$. This problem is, however, solved by standardising all the variables. The effect of standardisation is two-fold:

(i) The intercept of the regression model is zero, and more importantly

(ii) The standard regression coefficients are now comparable and are "a means of assessing the relative importance of each explanatory variable $x j$ included in the regression model: the variables with the highest standard regression coefficient (in absolute values) are those that contribute the most to the estimated $\dot{y}$ values" (Legendre and Legendre, 2012). In our case, using standardised annual balances, standardised winter precipitation and standardised summer temperature, the standard regression coefficients for winter precipitation and summer temperature are directly comparable and indicate the relative importance of summer temperature and winter precipitation for the annual mass balance.

For standardized variables, calculus with

$\boldsymbol{B}=\left(\mathbf{X}^{\prime} \cdot \mathbf{X}\right)^{-1} \cdot\left(\mathbf{X}^{\prime} \cdot \mathbf{Y}\right)$

as starting point (Legendre and Legendre, 2012), where $\mathbf{X}$ is a matrix of independent variables, $Y$ is the dependent variable and $\boldsymbol{B}$ is a vector of coefficients linking $\mathbf{X}$ and $Y$ in the regression equation, proof that the standard regression coefficients are estimated as:

$b_{1}=\frac{r_{x 1 y}-r_{x 1 x 2} \cdot r_{x 2 y}}{1-r_{x 1 x 2}^{2}}$
$b_{2}=\frac{r_{x 2 y}-r_{x 1 x 2} \cdot r_{x 1 y}}{1-r_{x 1 x 2}^{2}}$,

where $b_{1}$ and $b_{2}$ are the standard regression coefficients of the first and second independent variable, respectively, $r_{x 1 y}$ is the correlation between the first independent and the dependent variable, $r_{x 2 y}$ is the correlation between the second independent variable and the dependent variable and $r_{x 1 \times 2}$ is the correlation between the two independent variables.

Hence the standard regression coefficients, which are the relative importance of (in our case) winter precipitation and summer temperature for annual balance only depend on the correlations among winter precipitation, summer temperature and annual balance.

The difference between linear models and the climate index is that winter precipitation and summer temperature are 
individually weighted when using linear models, whereas the two independent variables are equally weighted when employing the climate index. Hence, the relative importances of summer temperature and winter precipitation are allowed to be different using linear models, whereas they are artificially kept similar using climate index models. Linear models were compared to models based on climate indices using $F$ tests.

In contrast to $p$ values and confidence bounds, Bayesian credible intervals are simple to interpret. We used the simplest possible Bayesian model, namely setting a uniform prior for the two standard regression coefficients for winter precipitation and summer temperature. This results in posterior distributions for the parameter estimates that are proportional to the maximum likelihood estimates of the parameter values. Bayesian credible intervals are simple to interpret and indicate the parameter space within which a parameter is found with a certain probability. In this study, we interpreted the relative importance of summer temperature and winter precipitation as different, when the median of the posterior distribution of one parameter was outside the 2.5 and 97.5 percentiles of the posterior distribution of the other parameter.

\subsubsection{Additive models}

In contrast to linear models, where coefficients link independent and dependent variables, this linking is achieved by a smoothing term in additive models

$\boldsymbol{y}=a+f_{1}\left(\boldsymbol{x}_{1}\right)+f_{2}\left(\boldsymbol{x}_{2}\right)$

(Zuur et al., 2009; Fig. 2). We used cubic regressions splines with three knots as smoothing terms. The number of knots was kept low to ensure monotony of the smoothing terms. The additive models were compared to linear models and climate index models by $F$ tests.

With the three statistical models proposed, we assume that errors in mass balance measurements are random and that climate data are error free. If the errors in mass balance measurements contain a systematic component, the estimates of relative importance of summer temperature and winter precipitation for annual balance are biased. If annual balances are systematically overestimated, the relative importance of summer temperature for annual balance is systematically underestimated.

\subsubsection{Cross-validation and analysis in running windows}

All the models were tested by calculating leave-one-out cross-validation (jack-knifing, e.g. Efron and Gong, 1983) and h-block cross-validation (Burman et al., 1994) where hsamples are left out on either side of the sample to be predicted. In this study we set $h$ to $2 . H$ block cross-validation is a powerful method to test effects of temporal autocorrelation in time-series. However, preliminary autocorrelation estimations revealed no significant $(p<0.05)$ AR(1) auto-
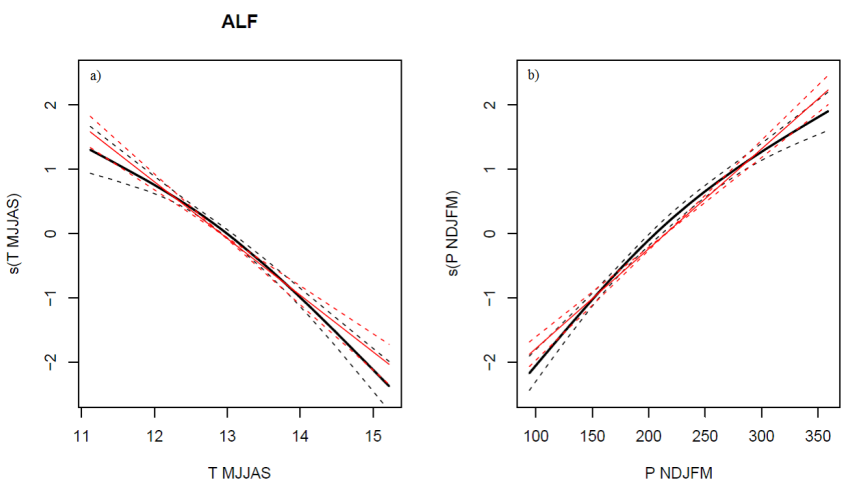

Figure 2. Additive model for Ålfotbreen. (a) Smooth term ( $S$ ( $T$ MJJAS); black) and linear model (red) for summer temperature (T MJJAS). (b) Smooth term ( $S$ ( $P$ NDJFM); black) and linear model (red) for winter precipitation $(P$ NDJFM). Dotted lines indicate confidence bounds.

correlation coefficients. We estimated cross-validated mean absolute deviations and coefficients of determination.

After running models for the entire observation period, we wanted to assess if the relative importance of summer temperature and winter precipitation changed through time and if these changes were consistent among the glaciers. For this purpose, we ran models in 25-year moving windows. The significance of changes in variance explained was again tested with $F$ Tests. According to these tests, additive models were never superior to linear models.

\subsubsection{Comparison to climate modes}

Preliminary analysis in running windows showed changes of relative importance of summer temperature and winter precipitation for annual balances that were consistent for all glaciers in southern Norway. We therefore assessed if these results were influenced by two large-scale patterns of oceanic and atmospheric variability over the north Atlantic realm. The North Atlantic Oscillation (NAO), an atmospheric pattern with an approximately decadal cyclicity (Hurrell et al., 2001; Wanner et al., 2001) and the Atlantic Multidecadal Oscillation (AMO), a pattern in sea-surface temperature that is linked to changes in thermohaline ocean circulation with a cyclicity of 65-70 years (Schlesinger and Ramankutty, 1994; Trenberth and Shea, 2006). The NAO mainly influences the strength and tracks of the westerlies and thereby the amount of winter precipitation in north-western Europe.

Nesje et al. (2000) and Marzeion and Nesje (2012) found strong and significant $(p<0.05)$ correlations between NAOindex and annual mass balances of glaciers in southern Norway, with correlations decreasing with increasing distance to the coast. For northern Norway, Marzeion and Nesje (2012) found insignificant or significantly negative $(p<0.05)$ correlations between NAO-index and annual mass balances. In this study, we adopt a different approach to assess the influ- 


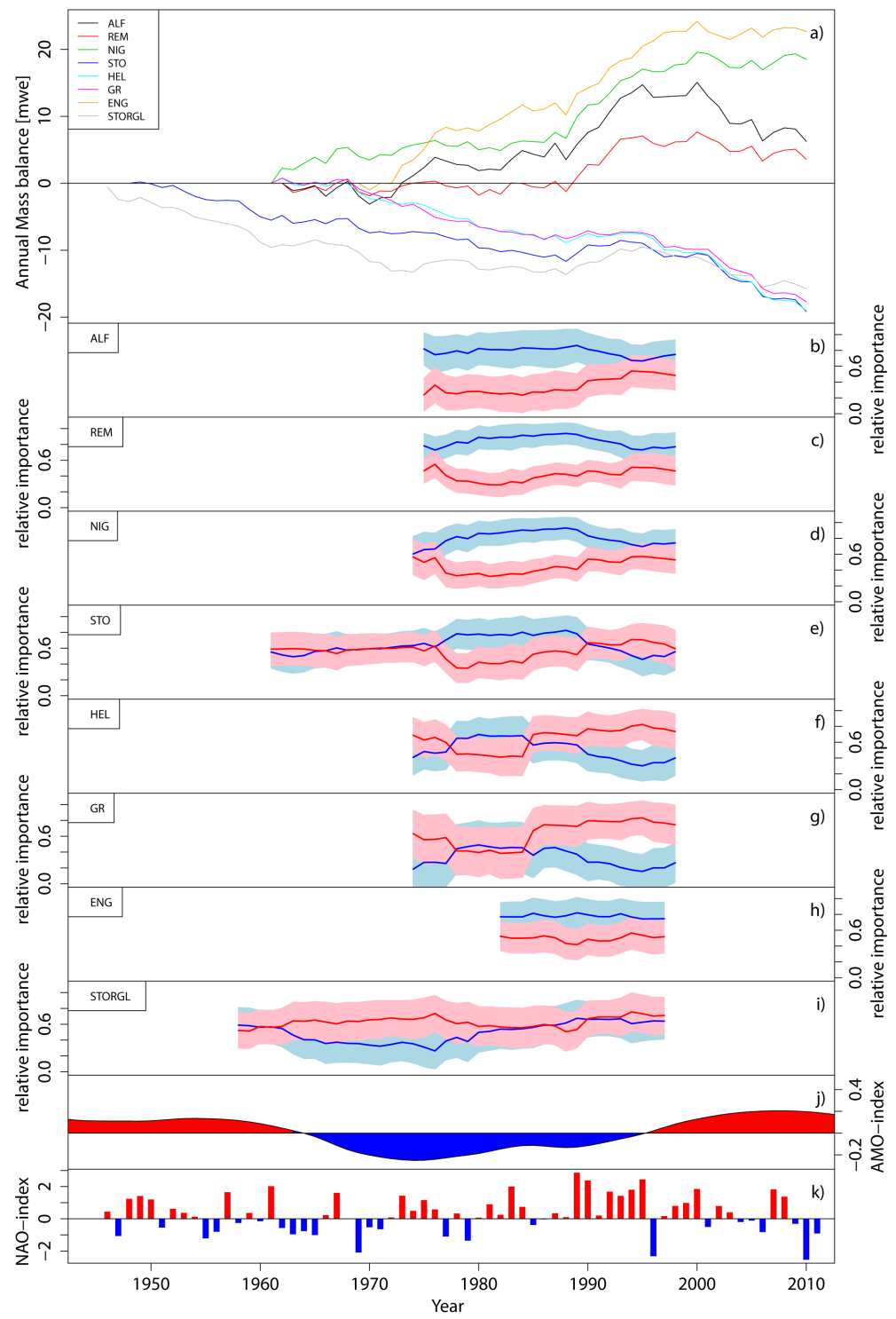

Figure 3. (a) Cumulative mass balances of Ålfotbreen (ALF), Rembesdalsskåka (REM), Nigardsbreen (NIG), Storbreen (STO), Hellstugubreen (HEL), Gråsubreen (GR), Engabreen (ENG) and Storglaciären (STORGL). Data: nve.no/bre (Norwegian glaciers) and bolin.su.se/data/tarfala (Storglaciären, northern Sweden). (b-i) Relative importance (standard regression coefficients) of winter precipitation (blue) and summer temperature (red) in 25-year moving windows. Blue (red) lines: median of estimated standard regression coefficients (relative importance) of winter precipitation (summer temperature). Light blue and pink shadings indicate 2.5 and $97.5 \%$ quantiles of Bayesian credible intervals of standard regression coefficients (relative importance). Results are presented as 25-year centred windows. (j) Atlantic Multidecadal Oscillation Index (http://www.esrl.noaa.gov/psd/data/timeseries/AMO/, 30-year loess-smoothed). (k) North Atlantic Oscillation Index (Jones et al., 1997, updated).

ence of the NAO on annual mass balances. We wanted to assess if the relative importance of summer temperature and winter precipitation were dependent on the NAO. Most of the glacier mass balance series investigated were shorter than 50 years. We therefore investigated the effects of changes in NAO by dividing the time series into two subsets with NAOindices above and below the median of the NAO-index for the period in which mass-balance measurements were available. We then estimated the relative importance of summer tem- perature and winter precipitation for the annual mass balance for these two subsets. We also wanted to assess if there were differences between the correlations between the NAO-index and winter mass balances and annual balances for years with above and below-median NAO-index. We also used the ratio of the standard deviation of the winter balance to the standard deviation of the annual balance $(\mathrm{sBw} / \mathrm{sBa})$ and the ratio of the standard deviation of the summer balance to the standard deviation of the annual balance (sBs / sBa) (e.g. Andreassen 
et al., 2005) to see if these ratios were different for mass balance data of years with above and below-median NAO-index.

Considering the period 1946-2010, the average monthly November through April precipitation in Bergen was $230 \mathrm{~mm}$ for the years with above-median NAO-index and $170 \mathrm{~mm}$ in the years with below-median NAO-index, which is significantly lower $(p<0.05)$.

The longest mass balance series started in 1946. The AMO was generally positive from ca. 1930-1962 and from 1997 to the present, whereas it was negative between 1963 and 1996. In the negative subset of the AMO, the correlation between the NAO-index and extended winter precipitation in Bergen was $r=0.82(p<0.05)$, whereas it was $r=0.56(p<0.05)$ for the years with predominantly positive AMO-index. The average November through April precipitation in Bergen was not differing between the two subsets $(200 \mathrm{~mm} /$ month). The average May through September temperature from BergenFlorida for the positive AMO subset was $14.4^{\circ} \mathrm{C}$, whereas it was $12.6^{\circ} \mathrm{C}$ in the negative AMO subset. Average T MJJAS for the period $1949-1962$ was $13.8^{\circ} \mathrm{C}$, which is also significantly $(p<0.05)$ higher than the average temperature in the negative AMO subset. As summer temperatures in Bergen were significantly $(p<0.05)$ higher in the positive AMO subset, we wanted to test if this altered the relative importance of summer temperature and winter precipitation for annual balances. This analysis was only carried out for the two long data series starting in 1946 and 1949. The data series were divided into two subsets of years of predominantly positive (1946/1949-1962, 1997-2010) and negative (1963-1996) AMO. We also estimated the ratios $\mathrm{sBw} / \mathrm{sBa}$ and sBs / sBa (e.g. Andreassen et al., 2005) with AMO+ and AMO-.

All calculations were done in R (R Core Team, 2014) and its add-on packages lmodel2 (Legendre, 2014), and mgcv (Wood, 2014).

\section{Results}

\subsection{Model performance}

The employed statistical models explained large proportions of the variance of annual mass balances (Table 1). For the maritime glaciers, the models explained more than $70 \%$ of the variance. The variance explained for continental glaciers varied between 50 and $70 \%$. Table 1 shows input variables, model types, variance explained by the most parsimonious models and standard regression coefficients of linear models (i.e. the relative importance of summer temperature and winter precipitation) and their Bayesian credible intervals. Cross-validated $r^{2}$ using leave-one-out cross-validation and h-block cross-validation were comparable to apparent $r^{2}$. The only exception was Ålfotbreen, where an additive model was most parsimonious. Cross-validated $r^{2}$ was reduced by 0.1 , i.e. the variance explained was reduced by $10 \%$ and linear models had higher $r^{2}$ under cross-validation. Crossvalidated mean absolute deviations were also lowest for the models chosen, except for Ålfotbreen where again linear models yielded lowest mean absolute deviations.

\subsection{Relative importance of summer temperature and winter precipitation}

For Storbreen, Engabreen and Storglaciären, the statistical models using climate indices as input variables were most parsimonious. These are the only glaciers where standard regression coefficients of linear models were not different (Table 1). Hence, linear models were also assigning about similar weights to summer temperature and winter precipitation for these three glaciers. For the maritime glaciers Rembesdalsskåka and Nigardsbreen, linear models indicated a higher relative importance of winter precipitation than of summer temperature, whereas for the continental glaciers Hellstugubreen and Gråsubreen, the relative importance of summer temperature was higher than the relative importance of winter precipitation. For the maritime Ålfotbreen, an additive model explained significantly $(p<0.05)$ more of the total variance than a linear model. The smooth terms of summer temperature and winter precipitation are shown in Fig. 2. The slope of the smooth for temperature was flatter than the slope of a linear model for below-average temperatures and steeper than the slope of a linear model for above-average temperatures. Hence the expected sensitivity of the annual mass balance for a change of $1{ }^{\circ} \mathrm{C}$ increased with increasing temperatures. In contrast, the slope of the smooth for precipitation was steeper than the slope of a linear model for belowaverage precipitation values and was flatter than the slope of a linear model for above-average precipitation levels. The expected sensitivity of the annual mass balance for a change in precipitation decreased with increasing precipitation.

\subsection{Changes in the relative importance of summer temperature and winter precipitation}

Temporal changes of relative importance of summer temperature and winter precipitation are shown in Fig. 3b-i. The relative importance of winter precipitation, as indicated by standard regression coefficients of winter precipitation in 25year running windows, was lowest at the end of the observation period. The relative importance of summer temperature, as indicated by standard regression coefficients of summer temperature in 25-year running windows, increased towards the end of the observation period (Fig. 3b-i).

Winter precipitation was more important than summer temperature for the annual balance of continental glaciers in southern Norway (STO, HEL, and GR) for the 25-year windows centred between 1977 and 1985. For STO, the period of higher relative importance of winter precipitation than relative importance of summer temperature was extended up to the 25-year window centred around 1990 (Fig. 3e). For the 
Table 1. Table of most parsimonious statistical models. Input variables used and model types are indicated along with apparent and crossvalidated variance explained. Cross-validated mean absolute deviations and relative importance of summer temperature (LM Coef $T$ ) and winter precipitation (LM Coef $P$ ) are indicated along uncertainties of estimates of relative importances. Relative importance of summer temperature and winter precipitation and apparent variance explained are also indicated for subsets only including years with above (NAO+) and below (NAO-) median NAO-index, years with negative AMO-index (AMO-) and for STO and STORGL years with positive AMO-index (AMO+). ALF (Ålfotbreen), REM (Rembesdalsskåka), NIG (Nigardsbreen), STORBR (Storbreen), HEL (Hellstugubreen), GR (Gråsubreen), ENG (Engabreen), STORGL (Storglaciären), Am: Additive Model, LM: Linear Model, CI: Climate Index, NAO: North Atlantic Oscillation, AMO: Atlantic Multidecadal Oscillation.

\begin{tabular}{|c|c|c|c|c|c|c|c|c|c|c|c|c|}
\hline Glacier & $\begin{array}{l}\text { Observation } \\
\text { period }\end{array}$ & $\begin{array}{l}\text { Input } \\
\text { variables }\end{array}$ & $\begin{array}{l}\text { Model } \\
\text { type }\end{array}$ & $\begin{array}{r}\text { Variance } \\
\text { explained }\end{array}$ & $\begin{array}{c}\text { Cross- } \\
\text { validated } \\
\text { var. exp. }\end{array}$ & $\begin{array}{r}\text { MAD } \\
\text { (m w.e.) }\end{array}$ & $\begin{array}{r}\text { LM } \\
\text { Coef. } \\
P\end{array}$ & $\begin{array}{l}\text { Lower } \\
\text { bound }\end{array}$ & $\begin{array}{l}\text { Upper } \\
\text { bound }\end{array}$ & $\begin{array}{r}\text { LM } \\
\text { Coef. } \\
T\end{array}$ & $\begin{array}{l}\text { Upper } \\
\text { bound }\end{array}$ & $\begin{array}{l}\text { Lower } \\
\text { bound }\end{array}$ \\
\hline ALF & $\begin{array}{l}\text { 1963-2010 } \\
\text { NAO+ } \\
\text { NAO- } \\
\text { AMO- }\end{array}$ & $\begin{array}{l}T \text { MJJAS } \\
P \text { NDJFM }\end{array}$ & $\mathrm{AM}$ & $\begin{array}{l}76 \\
73 \\
53 \\
75\end{array}$ & 66 & 0.66 & $\begin{array}{l}\mathbf{0 . 7 7} \\
0.58 \\
0.67 \\
\mathbf{0 . 8 5}\end{array}$ & $\begin{array}{l}0.62 \\
0.37 \\
0.37 \\
0.67\end{array}$ & $\begin{array}{r}0.92 \\
0.8 \\
0.97 \\
1.02\end{array}$ & $\begin{array}{l}-\mathbf{0 . 5 1} \\
-0.61 \\
-0.61 \\
\mathbf{- 0 . 2 7}\end{array}$ & $\begin{array}{r}-0.36 \\
-0.4 \\
-0.31 \\
-0.1\end{array}$ & $\begin{array}{r}-0.67 \\
-0.4 \\
-0.91 \\
-0.44\end{array}$ \\
\hline REM & $\begin{array}{l}\text { 1963-2010 } \\
\text { NAO+ } \\
\text { NAO- } \\
\text { AMO- }\end{array}$ & $\begin{array}{l}T \text { MJJAS } \\
P \text { NDJFM }\end{array}$ & LM & $\begin{array}{l}81 \\
82 \\
67 \\
85\end{array}$ & 78 & 0.37 & $\begin{array}{l}\mathbf{0 . 8 3} \\
\mathbf{0 . 7 8} \\
0.71 \\
\mathbf{0 . 8 8}\end{array}$ & $\begin{array}{r}0.7 \\
0.61 \\
0.46 \\
0.74\end{array}$ & $\begin{array}{l}0.96 \\
0.95 \\
0.96 \\
1.01\end{array}$ & $\begin{array}{l}-\mathbf{0 . 5 2} \\
-\mathbf{0 . 4 6} \\
-0.73 \\
-\mathbf{0 . 3 7}\end{array}$ & $\begin{array}{l}-0.39 \\
-0.29 \\
-0.48 \\
-0.23\end{array}$ & $\begin{array}{r}-0.64 \\
-0.63 \\
-0.98 \\
-0.5\end{array}$ \\
\hline NIG & $\begin{array}{l}\text { 1962-2010 } \\
\text { NAO+ } \\
\text { NAO- } \\
\text { AMO- }\end{array}$ & $\begin{array}{l}T \text { MJJAS } \\
P \text { NDJFM }\end{array}$ & LM & $\begin{array}{l}77 \\
76 \\
69 \\
78 \\
\end{array}$ & 73 & 0.45 & $\begin{array}{r}0.77 \\
0.69 \\
0.6 \\
0.82 \\
\end{array}$ & $\begin{array}{r}0.63 \\
0.5 \\
0.39 \\
0.66 \\
\end{array}$ & $\begin{array}{r}0.91 \\
0.9 \\
0.88 \\
0.99 \\
\end{array}$ & $\begin{array}{r}-\mathbf{0 . 5 7} \\
-\mathbf{0 . 5} \\
-0.75 \\
-\mathbf{0 . 4} \\
\end{array}$ & $\begin{array}{l}-0.43 \\
-0.31 \\
-0.49 \\
-0.24\end{array}$ & $\begin{array}{l}-0.75 \\
-0.71 \\
-0.98 \\
-0.56\end{array}$ \\
\hline STO & $\begin{array}{l}\text { 1949-2010 } \\
\text { NAO+ } \\
\text { NAO- } \\
\text { AMO+ } \\
\text { AMO- }\end{array}$ & $\begin{array}{l}T \text { MJJAS } \\
P \text { NDJFM }\end{array}$ & CI & $\begin{array}{l}68 \\
67 \\
63 \\
61 \\
75\end{array}$ & 66 & 0.32 & $\begin{array}{l}0.60 \\
0.58 \\
\mathbf{0 . 4 6} \\
\mathbf{0 . 4 7} \\
\mathbf{0 . 7 7}\end{array}$ & $\begin{array}{r}0.46 \\
0.37 \\
0.23 \\
0.23 \\
0.6\end{array}$ & $\begin{array}{l}0.75 \\
0.79 \\
0.69 \\
0.71 \\
0.94\end{array}$ & $\begin{array}{r}-0.66 \\
-0.6 \\
-\mathbf{0 . 7 9} \\
-\mathbf{0 . 7 3} \\
-\mathbf{0 . 4 7}\end{array}$ & $\begin{array}{r}-0.52 \\
-0.4 \\
-0.56 \\
-0.49 \\
-0.29\end{array}$ & $\begin{array}{r}-0.8 \\
-0.81 \\
-1.01 \\
-0.97 \\
-0.64\end{array}$ \\
\hline HEL & $\begin{array}{l}\text { 1962-2010 } \\
\text { NAO+ } \\
\text { NAO- } \\
\text { AMO- }\end{array}$ & $\begin{array}{l}T \text { JJA } \\
P \text { ONDJFMA }\end{array}$ & LM & $\begin{array}{l}69 \\
59 \\
74 \\
69\end{array}$ & 64 & 0.30 & $\begin{array}{l}\mathbf{0 . 4 5} \\
\mathbf{0 . 3 5} \\
\mathbf{0 . 3 9} \\
0.64\end{array}$ & $\begin{array}{l}0.29 \\
0.08 \\
0.18 \\
0.45\end{array}$ & $\begin{array}{l}0.61 \\
0.61 \\
0.62 \\
0.83\end{array}$ & $\begin{array}{l}-\mathbf{0 . 7 7} \\
\mathbf{- 0 . 6 8} \\
-\mathbf{0 . 9 2} \\
-0.52\end{array}$ & $\begin{array}{r}-0.61 \\
-0.32 \\
-0.7 \\
-0.33\end{array}$ & $\begin{array}{l}-0.93 \\
-0.93 \\
-1.14 \\
-0.71\end{array}$ \\
\hline GR & $\begin{array}{l}\text { 1962-2010 } \\
\text { NAO+ } \\
\text { NAO- } \\
\text { AMO- }\end{array}$ & $\begin{array}{l}T \text { JJA } \\
P \text { ONDJFMA }\end{array}$ & LM & $\begin{array}{l}54 \\
46 \\
60 \\
45\end{array}$ & 48 & 0.35 & $\begin{array}{l}\mathbf{0 . 3 0} \\
\mathbf{0 . 2 6} \\
\mathbf{0 . 2 1} \\
0.47\end{array}$ & $\begin{array}{r}0.1 \\
-0.04 \\
-0.08 \\
0.22\end{array}$ & $\begin{array}{l}0.49 \\
0.56 \\
0.47 \\
0.72\end{array}$ & $\begin{array}{l}-\mathbf{0 . 7 2} \\
\mathbf{- 0 . 6 2} \\
\mathbf{- 0 . 8 2} \\
-0.47\end{array}$ & $\begin{array}{l}-0.52 \\
-0.32 \\
-0.54 \\
-0.22\end{array}$ & $\begin{array}{l}-0.91 \\
-0.93 \\
-1.09 \\
-0.73\end{array}$ \\
\hline ENG & $\begin{array}{l}\text { 1970-2010 } \\
\text { NAO+ } \\
\text { NAO- } \\
\text { AMO- }\end{array}$ & $\begin{array}{l}T \text { MJJAS } \\
P \text { ONDJFMA }\end{array}$ & CI & $\begin{array}{l}74 \\
73 \\
72 \\
79\end{array}$ & 71 & 0.47 & $\begin{array}{r}0.713 \\
0.63 \\
0.76 \\
\mathbf{0 . 7 5}\end{array}$ & $\begin{array}{l}0.55 \\
0.39 \\
0.48 \\
0.58\end{array}$ & $\begin{array}{l}0.87 \\
0.86 \\
0.98 \\
0.93\end{array}$ & $\begin{array}{r}-0.59 \\
-0.63 \\
-0.7 \\
-\mathbf{0 . 5}\end{array}$ & $\begin{array}{l}-0.43 \\
-0.39 \\
-0.46 \\
-0.33\end{array}$ & $\begin{array}{l}-0.75 \\
-0.86 \\
-0.96 \\
-0.68\end{array}$ \\
\hline STORGL & $\begin{array}{l}\text { 1946-2010 } \\
\text { NAO+ } \\
\text { NAO- } \\
\text { AMO+ } \\
\text { AMO- }\end{array}$ & $\begin{array}{l}T \text { MJJAS } \\
P \text { NDJFM }\end{array}$ & $\mathrm{CI}$ & $\begin{array}{l}62 \\
54 \\
65 \\
62 \\
63\end{array}$ & 60 & 0.32 & $\begin{array}{l}0.53 \\
0.51 \\
\mathbf{0 . 4 5} \\
0.54 \\
0.58\end{array}$ & $\begin{array}{r}0.38 \\
0.27 \\
0.22 \\
0.3 \\
0.37\end{array}$ & $\begin{array}{l}0.68 \\
0.75 \\
0.63 \\
0.78 \\
0.79\end{array}$ & $\begin{array}{l}-0.60 \\
-0.59 \\
-\mathbf{0 . 6 8} \\
-0.62 \\
-0.52\end{array}$ & $\begin{array}{l}-0.45 \\
-0.34 \\
-0.49 \\
-0.38 \\
-0.31\end{array}$ & $\begin{array}{l}-0.75 \\
-0.83 \\
-0.89 \\
-0.86 \\
-0.73\end{array}$ \\
\hline
\end{tabular}

maritime glaciers in southern Norway, the Bayesian credible intervals of the standard regression coefficients (relative importances) were not overlapping for 25-year windows centred before 1990, but were overlapping for the last five running windows.

Storbreen indicated about equal importance of winter precipitation and summer temperature for 25-year windows ending prior to 1990 (Fig. 3e). The relative importance of summer temperature was higher than the relative importance of winter precipitation for 25-year windows centred in the first half of the 1970s for Storglaciären (Fig. 3i).

\subsection{NAO, AMO and annual balances}

The mass balance models for years with above- and belowmedian NAO-index, respectively, were different in terms of variance explained and in terms of relative importance assigned to summer temperature and winter precipitation. They 


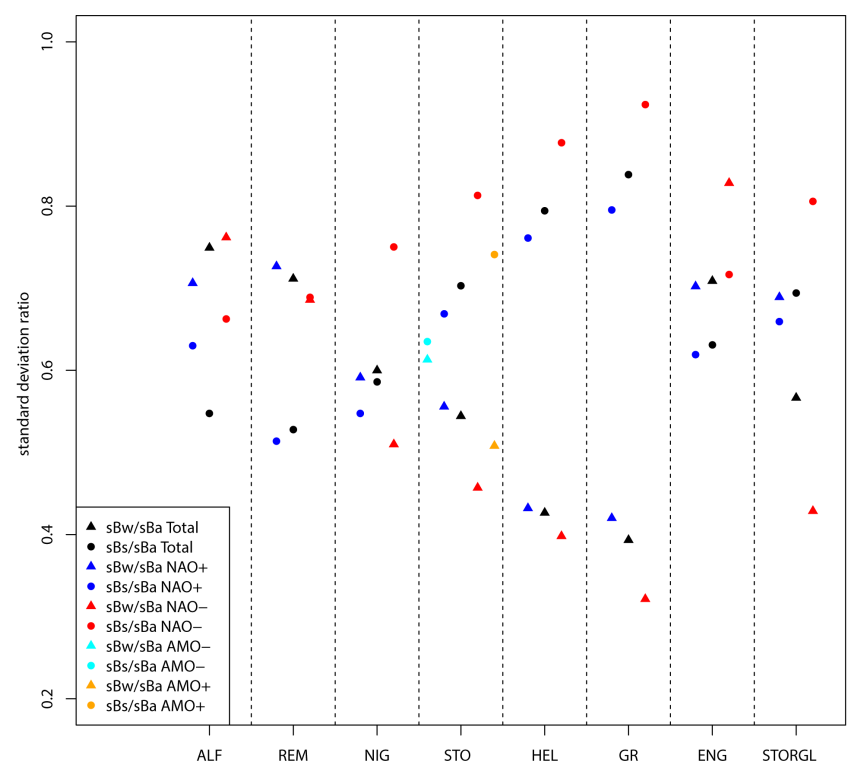

Figure 4. Standard deviation ratios. Ratios between standard deviations of winter balances $(\mathrm{sBw})$ and annual balances $(\mathrm{sBa}$, $\mathrm{sBw} / \mathrm{sBa}$, triangles) and summer balances (sBs) and annual balances (sBs / sBw, dots). Standard deviation ratios are shown for the entire measurement period (central symbols, black) and for periods of above (left symbols, blue) and below (right symbols, red) median NAO-index, respectively. For STO, standard deviations during $\mathrm{AMO}+$ (orange) and $\mathrm{AMO}-$ (cyan) are also indicated. sBw: standard deviation of winter mass balance, $\mathrm{sBs}$ : standard deviation of summer mass balance; sBa: standard deviation of annual mass balance.

also differed from models covering the entire measurement period.

For years with above-median NAO, models for Ålfotbreen, Rembesdalsskåka, Nigardsbreen and Storbreen explained as much of the variance of the mass balance as models for the entire data series, whereas for Hellstugubreen and Gråsubreen, the variance explained was reduced compared to the models for the entire period. Interestingly, for Ålfotbreen standard regression coefficients for winter precipitation and summer temperature were not different. For the phase with below-median NAO-index, models for Ålfotbreen, Rembesdalsskåka and Nigardsbreen explained less of the variance than in the entire period and standard regression coefficients for precipitation and temperature were not different, whereas models for Gråsubreen and Hellstugubreen explained more of the variance than in the entire period, and together with Storbreen displayed a higher importance of summer temperature than winter precipitation. The two glaciers with long data series had an average mass loss of $0.54 \mathrm{~m}$ water equivalents per year ( $\mathrm{m}$ w.e. $\mathrm{yr}^{-1}$ ) when the NAO-index was low, but an average gain of $0.03 \mathrm{~m}$ w.e. $\mathrm{yr}^{-1}$ for Storglaciären and an average loss of $0.08 \mathrm{~m}$ w.e. $\mathrm{yr}^{-1}$ for Storbreen with high NAO-index.

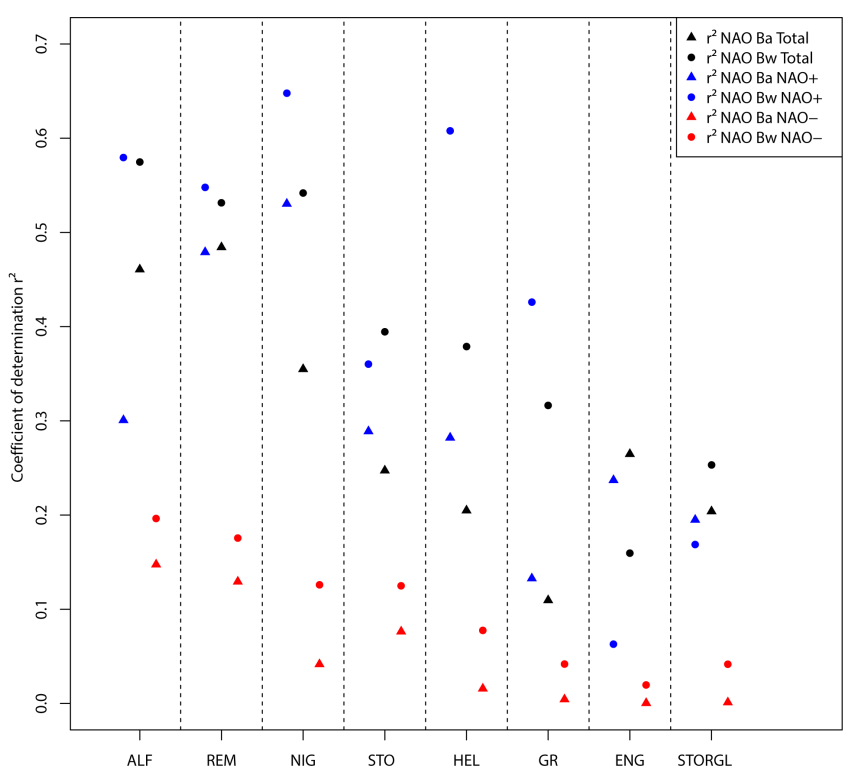

Figure 5. Coefficients of determination $\left(r^{2}\right)$ among mass balances and North Atlantic Oscillation (NAO) Index (Jones et al., 1997, updated). Coefficients of determinations are shown for the entire measurement period (central symbols, black) and for periods of above (left symbols, blue) and below (right symbols, red) median NAOindex, respectively. Bw: winter mass balance, Ba: annual mass balance; NAO: NAO-index.

For all glaciers, except for ALF, the ratio sBs / sBa was lower in years with above-median NAO-index than for the entire data series and the ratio $\mathrm{sBw} / \mathrm{sBa}$ was higher than for the entire data series for REM, STO, HEL, GR and STORGL (Fig. 4). For years with below-median NAO-index, the ratio $\mathrm{sBs} / \mathrm{sBa}$ was higher than in the entire data series and $\mathrm{sBw} / \mathrm{sBa}$ was lower than in the entire data series except for ALF and ENG (Fig. 4).

Correlations between NAO-index and winter and annual balance were different for the subsets of years with above and below-median NAO-index (Fig. 5). For glaciers in southern Norway, the correlation between NAO-index and winter and annual balance was higher than for the entire time series for years with above-median NAO-index and was lower than for the entire series for years with below-median NAOindex. For NIG, STO, HEL, GR, ENG and STORGL the correlation coefficients among NAO-index and $\mathrm{Ba}$ and $\mathrm{Bw}$ were not significant at the $p<0.05$ level for the subset of years with below-median NAO-index. For ALF and REM the correlation between NAO-index and $\mathrm{Ba}$ was not significant $(p<0.05)$ for the subset of years with below-median NAO-index.

Changes in relative importances of winter precipitation and summer temperature were also found for the $\mathrm{AMO}+$ and AMO - phases. The mass balance models for positive and negative AMO were differing for Storbreen in southern Norway (Table 1), whereas they remained unchanged for Stor- 
glaciären in northern Sweden. For Storbreen, the influence of winter precipitation was significantly higher than the influence of summer temperature with negative AMO-index, whereas the situation was opposite with positive AMO-index (Table 1). For both glaciers, the average annual mass balance was different in the two phases defined by positive and negative AMO indices: Storbreen lost an average of 0.5 and Storglaciären $0.48 \mathrm{~m}$ w.e. $\mathrm{yr}^{-1}$ when the AMO-index was positive, whereas the loss was reduced to averages of 0.15 and $0.02 \mathrm{~m}$ w.e. $\mathrm{yr}^{-1}$ for Storbreen and Storglaciären, respectively, when the AMO-index was negative. The AMO also affected the standard deviation ratios. For Storbreen, the ratios $\mathrm{sBs} / \mathrm{sBa}$ and $\mathrm{sBw} / \mathrm{sBa}$ were equal when the $\mathrm{AMO}$ was in its negative phase (Fig. 4). During the positive phase of the AMO, sBs / sBa was higher than sBw / sBa.

\section{Discussion}

\subsection{Model Performance}

We used simple statistical models that are only taking into account summer temperature and winter precipitation to model annual mass balances. Even though these models are simplistic, they explain large proportions of the variance of annual balances, and are therefore appropriate to estimate relative importance of summer temperature and winter precipitation for annual balances. The model performance is increased for coastal maritime glaciers. This might have several reasons: (i) precipitation is highly variable in space and therefore precipitation from Bergen is possibly more appropriate for coastal glaciers than for continental glaciers. Still, using precipitation from meteorological stations closer to the continental glaciers did not improve the model performance for continental glaciers. (ii) Processes not represented in our model are more important in summer (radiation) than in winter (wind redistribution of snow).

Climate sensitivities of Engabreen (Schuler et al., 2005), Rembesdalsskåka (Giesen and Oerlemans, 2010) and Storbreen (Andreassen and Oerlemans, 2009) show that summer balances are largely unaffected by changes in precipitation, which suggest minor importance of summer precipitation for summer balance. Still other important components such as the direct effect of radiation are not entirely accounted for when only using summer temperature to model ablation. Our models do not take into account the hypsometry of glaciers, which might be important in transitional seasons, where accumulation and ablation can occur simultaneously on one glacier (e.g. Schuler et al., 2005). Although our models do not account for these processes we get coefficients of determination similar to the values found by Rasmussen and Conway (2005) who used degree day models and RMSEPs lower or comparable to RMSEPs found by Engelhardt et al. (2013). This good performance of statistical models is probably due to the distinct accumulation and ablation seasons on Scandi- navian glaciers i.e. most accumulation occurring during winter and most ablation taking place during summer. In areas with less distinct accumulation and ablation seasons, statistical models using seasonally averaged climate variables will not perform well.

The application of statistical models using seasonally average climate as input variables seems especially interesting for two areas of application:

(i) Regions where only seasonal climate data are available (especially precipitation data) this problem can be overcome by using reanalysis data (e.g. Rasmussen and Conway, 2005). Rasmussen and Conway (2005) used reanalysis data for other reasons than lack of station data.

(ii) Palaeoclimate studies where reconstructed climate data are at maximum available at monthly resolution. For example Steiner et al. (2008) estimated the relative importance of changes in seasonally averaged precipitation and temperature during advance and retreat periods of Nigardsbreen and Lower Grindelwald Glacier (Swiss Alps) using artificial neural networks.

\subsection{Relative importance of summer temperature and winter precipitation}

Our results showed, as also demonstrated in other studies (Andreassen and Oerlemans, 2009; Giesen and Oerlemans, 2010; Laumann and Nesje, 2009a, b, 2014; Oerlemans, 1992), that the annual glacier mass balance on near coastal, maritime glaciers was mainly controlled by winter precipitation and that the annual mass balance on the inland, continental glaciers was mainly controlled by summer temperature (Andreassen et al., 2005; Nesje et al., 1995). Hence, standard regression coefficients of linear models are shown to be good estimators of the relative importance of summer temperature and winter precipitation for annual balances. The relative importance as determined by standard regression coefficients display similar patterns as the standard deviation ratios presented by Andreassen et al. (2005) and are also shown in Fig 4. The exceptions are NIG and STO. For NIG, standard regression coefficients indicate higher relative importance of winter precipitation compared to summer temperature, but standard deviation ratios are similar. Standard regression coefficients suggest equal relative importance of summer temperature and winter precipitation for STO, whereas the standard deviation ratio $\mathrm{sBs} / \mathrm{sBa}$ is higher than sBw / sBa. For both NIG and STO, climate sensitivities estimated by de Woul and Hock (2005) and Rasmussen and Conway (2005) using degree day models differ: de Woul and Hock (2005) estimate the precipitation increase needed to level a temperature increase of $1 \mathrm{~K}$ to be 30 and $50 \%$ for NIG and STO, respectively, whereas Rasmussen and Conway found lower values of 25 and $28 \%$. Engelhardt et al. (2013) also modelled mass balances of NIG and STO 
using degree day models. Modelled annual balances showed a strong positive bias for NIG and a strong negative bias for STO. Hence assessing the relative importance of winter precipitation and summer temperature on annual balances of NIG and STO seems difficult.

\subsection{Changes of relative importance of summer temperature and winter precipitation}

As shown in this study, the relative importance of summer temperature and winter precipitation for annual balances is not constant in time. Temporal changes in relative importance of summer temperature and winter precipitation are consistent for all of southern Norway (Fig. 3), suggesting common large-scale forcing of the relative importance of summer temperature and winter precipitation.

Maritime glaciers had a consistently positive mass balance between 1988 and 1996 and continental glaciers were no longer loosing mass (Fig. 3a, Nesje et al., 2000; Andreassen et al., 2005; Nesje and Matthews, 2012). Looking at the 25year windows centred between 1978 and 1984, we found that winter precipitation was more important than summer temperature for all glaciers including the continental glaciers in southern Norway, although the differences were not significant for the continental Gråsubreen. For the three continental glaciers in southern Norway, this phase was characterised by a marked decrease in relative importance of summer temperature and a marked increase in relative importance of winter precipitation.

In this phase, the AMO-index was consistently negative and the NAO-indexes were consistently positive between 1988 and 1996 (Fig. 3). In tendency, negative AMO indices were associated with reduced summer temperatures over Europe and positive NAO-indexes were associated with increased zonal flow in winter, entailing more winter precipitation in Northern Europe. Hence, the large-scale oceanic and atmospheric patterns were favourable for glacier growth.

As another example, in the 2000s all glaciers except Engabreen and Nigardsbreen generally experienced negative mass balances and mass balances of Engabreen and Nigardsbreen were at equilibrium. In this period, the importance of summer temperature for the annual mass balance was increased (Fig. 3), even though 25-year windows centred around 1997 still contained the years 1988-1996 with their transient mass surplus. The increasing relative importance of summer temperature and decreasing relative importance of winter precipitation for the annual balance at the end of the measurement period is consistent with more negative summer balances and less positive winter balances found for glaciers in southern Norway (e.g. Engelhardt et al. 2013). The AMO-index changed sign in the late 1990s and summer temperatures were in general higher than between 1985 and 1995.

For glaciers in the European Alps, Huss et al. (2010) found pronounced mass loss during phases of positive AMO-index and mass gain in phases of negative AMO-index, which is similar to findings in this study. The phases of increased glacier melt are, however, not simultaneous in the Swiss Alps and in Scandinavia. In the Swiss Alps, a pronounced mass loss lasting to the present day started in the late 1980s, whereas continental glaciers in Scandinavia lost mass between the start of the measurements and 1987 and all glaciers in Scandinavia lost mass after about 1998. This difference is most probably caused by the fact that changes in melt rates are most influential for mass balances in the Alps (Huss et al., 2010), whereas a decade with predominantly positive NAOindexes began in the late 1980s (1988/1989 winter) associated with increased relative importance of winter precipitation for Scandinavian glaciers (Fig. 3). This is in line with Marzeion and Nesje (2012) who found a positive correlation between the NAO and glaciers in southern Scandinavia, while a weak anti-correlation was found for the western Alps. This anti-correlation was diminishing towards east. Six et al. (2001) point out that anti-correlations between glacier mass balances in the alps and Scandinavia are mainly found in decadally smoothed data and attribute this to the NAO, whereas only weak anti-correlations are found using annual data.

\subsection{NAO, AMO and annual mass balances}

Clear differences are found between the subsets with abovemedian and below-median NAO-index. In winters with high NAO-index, stronger westerly flow and increased precipitation is expected (e.g. Wanner et al., 2001). The mass balance models of the maritime glaciers explained more of the total variance with high NAO-index and the relative importance of winter precipitation for the total mass balance was increased. This was according to expectations, as increased winter precipitation is expected to increase the importance of the winter precipitation for mass balance models.

For all glaciers, the correlation between NAO-index and winter and annual mass balance was higher for years with above-median NAO-index (Fig. 5). Additionally, the coefficient of determination between winter balance and NAOindex was decreased for the subset of years with belowmedian NAO-index (Fig. 5). This means that the reduction in coefficient of determination between NAO-index and annual balance was not only caused by an increased importance of the summer balance for the annual balance, but also by a loss of accordance between NAO-index and winter balance. This loss in accordance is only partly caused by lower accordance among precipitation in Bergen and winter balances, but mainly by a consistently decreased correlation between the NAO-index and precipitation in Bergen. Consequently the NAO-index is only a good predictor for winter balances of glaciers in southern Norway in years with above-median NAO-index. This is reiterating a find by Six et al. (2001), who do not recommend to model glacier mass balances solely based on the NAO-index. Unstable relations 
between the NAO-index and glacier length changes in Scandinavia as well as in the Alps were also found by Imhof et al. (2011).

For the two glaciers with long mass balance time-series, the influence of the NAO seemed equal to the influence of the AMO, as the difference between the average mass balances in the two NAO levels considered was about equal to the difference in the two AMO states. The AMO states only include consecutive years, whereas individual years were assigned to the NAO-index. The phase between ca. 1987 and 1995 with major mass gain for maritime glaciers and neutral mass balances for continental glaciers was characterised by negative AMO-index and predominantly positive NAOindex, that were both favourable for glaciers.

The relation between AMO and NAO seems rather complex and depends on the timescale considered (Li et al., 2013; Peings and Magnusdottir, 2014). On short timescales, the atmospheric NAO pattern influences the sea surface temperature, whereas on longer timescales, the sea-surface temperature AMO pattern drives the atmospheric NAO. Hence Li et al. (2013) find the NAO to lead the AMO by 16 years and state that the NAO is an excellent predictor for AMO and thereby Northern Hemisphere temperature, whereas Peings and Magnusdottir (2014) find "that the multidecadal fluctuations of the wintertime North Atlantic Oscillation (NAO) are tied to the AMO, with an opposite signed relationship between the polarities of the AMO and the NAO. Our statistical analyses suggest that the AMO signal precedes the NAO by $10-15$ years".

The association of negative AMO and positive NAO seems to be typical (Peings and Magnusdottir 2014), whereas positive AMO favours negative NAO and blocking situations. For the time period 1965-1998, with negative AMO, only 10 years have a negative NAO-index, whereas for the considerably shorter phase 1999-2010 already 6 years had a negative NAO-index. Hence, the two modes favouring glacier mass gain and mass loss, respectively, tended to occur simultaneously. However, the influence of AMO and NAO should not be overestimated, as similar weather patterns still result in different amounts of precipitation and in different levels of temperature (Jacobeit et al., 2003; Kuettel et al., 2011). Kuettel et al. (2011), for instance, attribute $60 \%$ of the changes of winter precipitation over southern Norway between the periods 1900-1949 and 1950-1999 to changes within weather patterns and only $40 \%$ to changes in frequencies of weather patterns.

\section{Conclusions}

We used simple statistical models to assess the relative importance of summer temperature and winter precipitation for annual balances of eight glaciers in Scandinavia. The relative importances found using statistical models were comparable to estimates of relative importance obtained using different methods. Most importantly, the relative importance of summer temperature and winter precipitation for annual balances varied through time. Winter precipitation was most important when the Atlantic Multidecadal Oscillation Index was negative and the North Atlantic Oscillation Index was positive. Presently, the relative importance of winter precipitation decreased for all glaciers while the relative importance of summer temperature was increasing. The influence of NAO and $\mathrm{AMO}$ on the relative importance of summer temperature and winter precipitation for annual balance was confirmed considering subsets of different NAO and AMO levels, with increasing relative importance of winter precipitation in years with $\mathrm{NAO}+$ and $\mathrm{AMO}-$ and increased relative importance of summer temperature in years with $\mathrm{AMO}+$ and $\mathrm{NAO}-$. The relation between NAO and winter balances was lost only considering years with low NAO-index.

\section{The Supplement related to this article is available online at doi:10.5194/tc-9-1401-2015-supplement.}

Acknowledgements. We would like to thank two reviewers for comprehensive comments that improved the clarity of this manuscript. We also thank Pascal Hänggi for comments on an earlier version of this manuscript and Heinz Wanner for discussion of large-scale climate patterns as the NAO and the AMO.

Edited by: J. O. Hagen

\section{References}

Andreassen, L. M. and Oerlemans, J.: Modelling Long-Term Summer and Winter Balances and the Climate Sensitivity of Storbreen, Norway, Geogr. Ann. Ser.-Phys. Geogr., 91, 233-251, 2009.

Andreassen, L. M. and Winsvold, S. H.: Inventory of Norwegian Glaciers. Norwegian Water Resources and Energy Directorate, Rapport 38-2012, NVE, Oslo, 2012.

Andreassen, L. M., Elvehoy, H., Kjollmoen, B., Engeset, R. V., and Haakensen, N.: Glacier mass-balance and length variation in Norway, Ann. Glaciol., 42, 317-325, 2005.

Andreassen, L. M., Elvehøy, H., Johannesson, T., Oerlemans, J., Beldring, S., and van den Broeke, M.: Modelling the climate sensitivity of Storbreen and Engabreen, Norway. Norwegian Water Resources and Energy Directorate, Report no. 3, NVE, Oslo, 2006.

Bakke, J., Dahl, S. O., Paasche, O., Lovlie, R., and Nesje, A.: Glacier fluctuations, equilibrium-line altitudes and palaeoclimate in Lyngen, northern Norway, during the Lateglacial and Holocene, Holocene, 15, 518-540, 2005.

Burman, P., Chow, E., and Nolan, D.: A Cross-Validatory Method for Dependent Data, Biometrika, 81, 351-358, 1994.

De Woul, M. and Hock, R.: Static mass-balance sensitivity of Arctic glaciers and ice caps using a degree-day approach, Ann. Glaciol., 42, 217-224, 2005. 
Efron, B. and Gong, G.: A Leisurely Look at the Bootstrap, the Jackknife, and Cross-Validation, Am. Stat., 37, 36-48, 1983.

Engelhardt, M., Schuler, T. V., and Andreassen, L. M.: Glacier mass balance of Norway 1961-2010 calculated by a temperature-index model, Ann. Glaciol., 54, 32-40, 2013.

Giesen, R. H. and Oerlemans, J.: Response of the ice cap Hardangerjokulen in southern Norway to the 20th and 21st century climates, Cryosphere, 4, 191-213, 2010.

Hock, R., Radic, V., and De Woul, M.: Climate sensitivity of Storglaciaren, Sweden: an intercomparison of mass-balance models using ERA-40 re-analysis and regional climate model data, Ann. Glaciol., 46, 342-348, 2007.

Hurrell, J. W., Kushnir, Y., and Visbeck, M.: The North Atlantic Oscillation, Science, 291, 603-605, 2001.

Huss, M., Hock, R., Bauder, A., and Funk, M.: 100-year mass changes in the Swiss Alps linked to the Atlantic Multidecadal Oscillation, Geophys. Res. Lett., 37, L10501, doi:10.1029/2010GL042616, 2010.

Imhof, P., Nesje, A., and Nussbaumer, S. U.: Climate and glacier fluctuations at Jostedalsbreen and Folgefonna, southwestern Norway and in the western Alps from the "Little Ice Age" until the present: The influence of the North Atlantic Oscillation, Holocene, 22, 235-247, 2012.

IPCC: Climate Change 2007: The Physical Science Basis Working Group I Contribution to the Fourth Assessment Report of the IPCC, Camb. Univ. Press, available from: http://www.cambridge.org/no/academic/ (last access: 13 December 2014), 2007.

IPCC: Climate Change 2013: The Physical Science Basis. Contribution of Working Group I to the Fifth Assessment Report of the Intergovernmental Panel on Climate Change, Camb. Univ. Press, available from: http://www.cambridge.org/no/academic/subjects/ (last access: 13 December 2014), 2013.

Jacobeit, J., Wanner, H., Luterbacher, J., Beck, C., Philipp, A., and Sturm, K.: Atmospheric circulation variability in the NorthAtlantic-European area since the mid-seventeenth century, Clim. Dyn., 20, 341-352, 2003.

Jones, P. D., Jonsson, T., and Wheeler, D.: Extension to the North Atlantic Oscillation using early instrumental pressure observations from Gibraltar and south-west Iceland, Int. J. Climatol., 17, 1433-1450, 1997.

Kjøllmoen, B. (Ed.): Glaciological investigations in Norway 2010, Norwegian Water Resources and Energy Directorate. Rapport, 3.NVE, Oslo, 2011.

Kuettel, M., Luterbacher, J., and Wanner, H.: Multidecadal changes in winter circulation-climate relationship in Europe: frequency variations, within-type modifications, and long-term trends, Clim. Dyn., 36, 957-972, 2011.

Laumann, T. and Nesje, A.: A simple method of simulating the future frontal position of Briksdalsbreen, western Norway, Holocene, 19, 221-228, 2009a.

Laumann, T. and Nesje, A.: The impact of climate change on future frontal variations of Briksdalsbreen, western Norway, J. Glaciol., 55, 789-796, 2009b.

Laumann, T. and Nesje, A.: Sporteggbreen, western Norway, in the past, present and future: Simulations with a two-dimensional dynamical glacier model, Holocene, 24, 842-852, 2014.
Legendre, P.: lmodel2: Model II Regression, available from: http: //cran.r-project.org/web/packages/lmodel2/index.html (last access: 13 December 2014), 2014.

Legendre, P. and Legendre, L.: Numerical Ecology, 3rd Edn., Elsevier, Amsterdam, 2012.

Li, J., Sun, C., and Jin, F.-F.: NAO implicated as a predictor of Northern Hemisphere mean temperature multidecadal variability, Geophys. Res. Lett., 40, 5497-5502, 2013.

Marzeion, B. and Nesje, A.: Spatial patterns of North Atlantic Oscillation influence on mass balance variability of European glaciers, Cryosphere, 6, 661-673, 2012.

Mernild, S. H., Hanna, E., Yde, J. C., Seidenkrantz, M.-S., Wilson, R. and Knudsen, N. T.: Atmospheric and Oceanic Influence on Mass Balance of Northern North Atlantic Region LandTerminating Glaciers, Geogr. Ann. Ser.-Phys. Geogr., 96, 561577, 2014.

Nesje, A.: Briksdalsbreen in western Norway: AD 1900-2004 frontal fluctuations as a combined effect of variations in winter precipitation and summer temperature, Holocene, 15, 12451252, 2005.

Nesje, A.: Latest Pleistocene and Holocene alpine glacier fluctuations in Scandinavia, Quat. Sci. Rev., 28, 2119-2136, 2009.

Nesje, A., Johannessen, T., and Birks, H.: Briksdalsbreen, Western Norway - Climatic Effects on the Terminal Response of a Temperate Glacier Between Ad 1901 and 1994, Holocene, 5, 343 347, 1995.

Nesje, A., Lie, O. and Dahl, S. O.: Is the North Atlantic Oscillation reflected in Scandinavian glacier mass balance records?, J. Quat. Sci., 15, 587-601, 2000.

Oerlemans, J.: Climate Sensitivity of Glaciers in Southern Norway - Application of an Energy-Balance Model to Nigardsbreen, Hellstugubreen and Alfotbreen, J. Glaciol., 38, 223-232, 1992.

Oerlemans, J.: A flowline model for Nigardsbreen, Norway: projection of future glacier length based on dynamic calibration with the historic record, Ann. Glaciol., 24, 382-9, 1997.

Peings, Y. and Magnusdottir, G.: Forcing of the wintertime atmospheric circulation by the multidecadal fluctuations of the North Atlantic ocean, Environ. Res. Lett., 9, 034018, doi:10.1088/1748-9326/9/3/034018, 2014.

R Core Team: R: A Language and Environment for Statistical Computing. R Foundation for Statistical Computing, Vienna, Austria, 2014.

Rasmussen, L. A. and Conway, H.: Influence of upper-air conditions on glaciers in Scandinavia, in Annals of Glaciology, Ann Glaciol., 42, 402-408, 2005.

Rasmussen, L. A., Andreassen, L. M., and Conway, H.: Reconstruction of mass balance of glaciers in southern Norway back to 1948, Ann. Glaciol., 46, 255-60, 2007.

Schlesinger, M. and Ramankutty, N.: An Oscillation in the Global Climate System of Period 65-70 Years, Nature, 367, 723-726, 1994.

Schuler, T. V., Hock, R., Jackson, M., Elvehoy, H., Braun, M., Brown, I., and Hagen, J.-O.: Distributed mass-balance and climate sensitivity modelling of Engabreen, Norway, Ann. Glaciol., 42, 395-401, 2005.

Six, D., Reynaud, L., and Letreguilly, A.: Alpine and Scandinavian glaciers mass balances, their relations with the North Atlantic Oscillation., Comptes Rendus Acad. Sci. Ser. Ii Fasc.-Sci., 333, 693-698, 2001. 
Steiner, D., Pauling, A., Nussbaumer, S. U., Nesje, A., Luterbacher, J., Wanner, H., and Zumbuehl, H. J.: Sensitivity of European glaciers to precipitation and temperature - two case studies, Climate Change, 90, 413-441,2008.

Trenberth, K. E. and Shea, D. J.: Atlantic hurricanes and natural variability in 2005, Geophys. Res. Lett., 33, L12704, doi:10.1029/2006GL026894, 2006.
Wanner, H., Bronnimann, S., Casty, C., Gyalistras, D., Luterbacher, J., Schmutz, C., Stephenson, D. B., and Xoplaki, E.: North Atlantic Oscillation - Concepts and studies, Surv. Geophys., 22, 321-382, 2001.

Wood, S.: mgcv: Mixed GAM Computation Vehicle with GCV/AIC/REML smoothness estimation, available from: http: //cran.r-project.org/web/packages/mgcv/index.html, last access: 13 December 2014.

Zuur, A. F., Ieno, E. N., Walker, N. J., Saveliev, A. A., and Smith, G. M.: Mixed Effects Models and Extensions in Ecology with R, Springer, Berlin, 2009. 